\title{
Contribuição do curso de especialização em Atenção Primária à Saúde à prática de profissionais da saúde
}

\section{Contribution of the specialization course in Primary Health Care to the practice of health professionals}

\author{
Luciana Bisio Mattos ${ }^{1}$, Alessandra Dahmer ${ }^{2}$, Cleidilene Ramos Magalhães ${ }^{1,3}$
}

${ }^{1}$ Programa de Pós-Graduação em Ciências da Saúde, Universidade Federal de Ciências da Saúde de Porto Alegre (UFCSPA) - Porto Alegre (RS), Brasil. 2Departamento de Ciências Exatas e Sociais Aplicadas, UFCSPA - Porto Alegre (RS), Brasil.

${ }^{3}$ Departamento de Educação e Humanidades, UFCSPA - Porto Alegre (RS), Brasil.

\section{RESUMO}

Introdução: Este estudo situa-se no escopo da educação permanente em saúde, ferramenta que tem sido fundamental para provocar mudanças nas práticas do trabalho em saúde. Neste cenário, a prática da atenção primária à saúde, em especial a saúde da família, tem sido utilizada para efetivar a organização dos serviços de saúde no Brasil. Objetivo: Analisar a contribuição de um curso de especialização em Saúde da Família, nas modalidades presencial e à distância, para a prática de profissionais de saúde no estado do Rio Grande do Sul. Métodos: Trata-se de um estudo qualitativo, realizado no contexto de um curso de especialização em Saúde da Família, ofertado por duas instituições em Porto Alegre, utilizando-se um questionário on-line e um grupo focal. Resultados: Os participantes do estudo foram 64 profissionais de saúde (médicos, enfermeiros e odontólogos) que já atuavam na atenção primária à saúde e integraram as turmas nas modalidades presencial e à distância. Foram realizados dois grupos focais (durante o início e ao final do curso), além de terem sido analisadas as percepções dos profissionais em relação à contribuição do curso na prática profissional. Conclusão: O curso provocou mudanças, tais como reorganização do processo de trabalho da equipe, implementação de atividades coletivas e acolhimento à demanda espontânea, além de maior compreensão do processo de trabalho.

Palavras-chave: educação em saúde; atenção primária à saúde; saúde da família.

\begin{abstract}
Introduction: This study lies within the scope of health permanent education, a tool that has been essential in causing changes in health work practices. In this scenario, the practice of primary health care, especially family health, has been used to carry out the organization of health services in Brazil. Objective: To analyze the contribution of a specialization course in Family Health, in present and distant modes, to the practice of health professionals in the state of Rio Grande do Sul. Methods: This is a qualitative study conducted in the context of a specialization course in Family Health that is offered by two institutions in Porto Alegre, using an online questionnaire and a focal group. Results: Study participants were 64 health professionals (physicians, nurses and dentists) that were already working in primary health care and formed the classes in present and distant modes. Two focal groups were conducted (during the beginning and by the end of the course), and professionals' perceptions regarding the contribution of the course to the professional practice was analyzed. Conclusion: The course caused some changes, such as reorganization of teamwork process, implementation of collective activities and reception to spontaneous demand, as well as better understanding of the work process.
\end{abstract}

Keywords: health education; primary health care; family health.

Recebido em: 10/08/2015

Revisado em: 19/09/2015

Aprovado em: 25/09/2015

Autor para correspondência: Luciana Bisio Mattos - Universidade Federal de Ciências da Saúde de Porto Alegre - Rua Sarmento Leite, 245 - sala 412 CEP: 90050-170 - Porto Alegre (RS), Brasil - E-mail: lubisiomattos@yahoo.com.br

Fonte de financiamento: Fundação de Amparo à Pesquisa do Estado do Rio Grande do Sul (FAPERGS), Coordenação de Aperfeiçoamento de Pessoal de Nível Superior (Capes) e Ministério da Saúde.

Conflito de interesses: nada a declarar. 


\section{INTRODUÇÃO}

No Brasil, a Constituição Federal de 1988, fortemente influenciada pelas conferências nacionais e internacionais de saúde, bem como pelas novas perspectivas políticas e sanitárias do país, criou um novo arranjo na saúde pública ${ }^{1}$. Como resultado desse cenário, o Sistema Único de Saúde (SUS) foi implementado em setembro de 1990, por meio da Lei n. 8.080, que estabelece como princípios a universalidade do acesso, a integralidade do cuidado e a equidade das ações². Tal fato acaba por desencadear uma série de mudanças nos serviços de saúde pública brasileiros, sendo escolhido como prioritário, para a garantia de tais princípios, outro modelo assistencial e de cuidado, a Atenção Primária à Saúde (APS).

A APS, mais conhecida no Brasil como atenção básica, deve constituir o primeiro contato do sujeito com o sistema de saúde, ou seja, a sua porta de entrada, que tem como características a universalidade, a acessibilidade, o vínculo, a continuidade do cuidado, a integralidade da atenção, a responsabilização, a humanização, a equidade e a participação social ${ }^{3}$. Atualmente, no Brasil, a APS considera a saúde da família como uma estratégia prioritária para a sua organização, tendo como principal desafio promover a reorientação das práticas e das ações de saúde de forma integral e contínua, levando-as para mais perto da família e, com isso, melhorando a qualidade de vida dos brasileiros.

A adoção deste novo arranjo organizacional pelo SUS aumentou a importância estratégica da área de recursos humanos, enfatizando, em especial, os processos educativos significativos, seja na graduação ou no trabalho em saúde ${ }^{4}$. Essa necessidade é justificada pelos princípios que regem o processo de trabalho em saúde: a característica relacional, isto é, o trabalho acontece no momento do encontro entre usuário e trabalhador (intersubjetividade), exigindo uma capacidade de reflexão constante, pois é constituído de descontinuidades e incertezas, o que impossibilita "programar" e padronizar ações, intervenções e atividades antes de entrar em contato com as situações ${ }^{5}$.

Por meio do uso dessa matriz, o Ministério da Saúde (MS) produziu uma série de aproximações no sentido de facilitar a compreensão da necessidade de extrapolar a lógica da educação tradicional, a qual privilegia a atualização do conhecimento técnico de cada profissão em prol de um esforço transnacional de qualificação do setor de saúde, por meio da Política de Educação Permanente em Saúde (EPS)

Nesse sentido, a EPS é o conceito pedagógico sob o qual devem operar relações orgânicas que articulem tanto o ensino e as ações e os serviços de saúde como a docência e atenção à saúde, relacionando aprendizado/reflexão/resolutividade sobre o trabalho e a clínica e aproximando a educação da realidade cotidiana e concreta ${ }^{7,8}$.

Diante da importância de qualificar e aperfeiçoar as práticas em APS e ampliar as possibilidades da formação de recursos humanos, várias instituições têm centrado esforços na EPS de seus profissionais. Nos últimos anos, esse fortalecimento também tem sido potencializado pela oferta de cursos nas modalidades presencial e à distância, destinada principalmente aos profissionais que já estão atuando nos serviços de saúde.

Dessa forma, este estudo teve por objetivo analisar a contribuição do curso de especialização em Saúde da Família, nas turmas oferecidas em 2012, nas modalidades presencial e à distância, para a prática de profissionais de saúde, bem como as mudanças ocorridas nas execuções dos trabalhos dos participantes, por meio da percepção destes. Além disso, buscou analisar a EPS como uma estratégia ao aprimoramento da prática de profissionais no Rio Grande do Sul.

\section{MÉTODOS}

Trata-se de uma pesquisa qualitativa, realizada entre abril de 2012 e dezembro de 2013, que versa sobre a oferta do curso de especialização em Saúde da Família, nas modalidades presencial, oferecida pela Associação Hospitalar Moinhos de Vento, e à distância, pela Universidade Aberta do SUS (UNA/SUS) e Universidade Federal de Ciências da Saúde de Porto Alegre (UFCSPA). O objetivo foi qualificar 64 profissionais de nível superior (Medicina, Enfermagem e Odontologia), distribuídos em 26 alunos para a turma presencial e 38 para ensino à distância $(\mathrm{EaD})$, integrantes das equipes da Estratégia Saúde da Família (ESF), do Rio Grande do Sul. Ambos os grupos possuem desenho pedagógico semelhante, sendo apenas a modalidade diferenciada. Com carga horária de 390 horas, o curso tem duração mínima de 18 meses e máxima de 36 meses $^{9,10}$.

O estudo foi desenvolvido em várias etapas, como descrito a seguir:

- Sorteio dos participantes (informados no ato da inscrição) para as duas modalidades de curso (presencial e à distância);

- Aplicação de um questionário on-line a todos os participantes do curso (64), a fim de caracterizar os sujeitos da pesquisa;

- Formação de dois grupos focais entre médicos, enfermeiros e dentistas (um com participantes da modalidade presencial e outro com sujeitos da modalidade à distância);

- Realização do grupo focal (no início e ao final do curso) com um roteiro de perguntas, incluindo temáticas referentes às aprendizagens no curso e à contribuição destas na prática dos profissionais ${ }^{11}$. O número de participantes do grupo focal foi entre seis e nove pessoas. A sua sessão teve um coordenador (pesquisadora) e um relator. Os encontros tiveram duração de aproximadamente 90 minutos e foram gravados em áudio e vídeo.

Quanto aos procedimentos da análise, para os dados obtidos no questionário on-line, utilizou-se a estatística descritiva (média e desvio padrão) para variáveis contínuas, e percentuais para categóricas, por meio do programa SPSS versão 19. Para os dados obtidos no grupo focal, empregou-se a técnica de análise temática ou categorial para os dados qualitativos, que se baseia no desmembramento do texto em unidades, com o objetivo de descobrir os diferentes sentidos que constituem a comunicação ${ }^{12}$.

\section{RESULTADOS E DISCUSSÃO}

\section{Caracterização dos participantes do curso}

Dos 64 alunos do curso, apenas 42 responderam na íntegra ao questionário on-line. Destes, 35 (83,3\%) eram do sexo feminino e sete 
$(16,7 \%)$ do masculino. Cinco $(11,9 \%)$ sujeitos estavam atuando em Porto Alegre; a maior parte era do núcleo de enfermagem, 27 (64,3\%); apenas quatro (9,5\%) de medicina e 11 (26,2\%) de odontologia. Esses dados corroboram outros estudos em relação ao perfil dos trabalhadores que frequentam cursos de especialização, nos quais os enfermeiros tiveram a maior participação (61\%) e o núcleo médico, a menor ${ }^{13}$.

Quanto à modalidade de atuação dos trabalhadores/alunos, 69,7\% referiram estar trabalhando em equipes da ESF e 24,2\% em Unidades Básicas de Saúde (UBS) tradicionais, com tempo médio de atuação na atual equipe de saúde de 21 meses.

A partir da análise das produções dos grupos focais, foram compostas algumas categorias, distribuídas em dois eixos: relação com o processo de formação no curso de especialização e relação do curso de especialização com a prática de trabalho.

\section{Relação com o processo de formação no curso de especialização}

Nesse eixo, percebe-se a similaridade da motivação para o curso em ambas as turmas, tendo sido trazidas, como principais bases para discussão, a importância de compartilhar saberes, a troca de experiências, a gratuidade do curso e a possibilidade de aprofundar conhecimentos para uma qualificação em saúde da família. Essas ideias são explicitadas em algumas falas:

Eu sempre gostei também da saúde coletiva, sempre foi o meu sonho trabalhar em Estratégia Saúde da Família. Daí, passei num concurso e estava no céu, comecei a trabalhar e vi que a minha formação é voltada só para a área hospitalar [...]. Tem pouca coisa dessa área de saúde pública, então, eu senti muita necessidade, estava procurando uma pós-graduação em Saúde da Família [...].

A ampliação da visão e a conscientização do processo de trabalho na equipe foram temas recorrentes como aprendizagem percebida pelos trabalhadores/alunos, além da aquisição de novas ferramentas de trabalho como estratégia ao enfrentamento de situações complexas no cotidiano, assim como a organização de agenda e a estrutura de acesso ao serviço de saúde. Essas percepções vêm ao encontro dos achados descritos em uma pesquisa também realizada sobre um curso de especialização em Saúde da Família, no estado da Bahia, em que, nas questões dissertativas do estudo, a maioria dos participantes referiu que, após o curso, teve um melhor entendimento de seu processo de trabalho, com uma extensão da capacidade de análise crítica e incorporação de novas tecnologias em $\mathrm{APS}^{14}$, assim como explicitam as falas dos participantes deste estudo:

A visão de saúde da família ampliou muito para mim, eu não tinha uma ideia, mesmo trabalhando há bastante tempo nisso, do quanto isso estava grande e espalhado por todo o Brasil, né? Hoje são muitas equipes, a cobertura de [Estratégia] Saúde da Família é bem grande, né, e a gente às vezes, lá no nosso local, não faz ideia da grandiosidade desse movimento, da estratégia, de toda essa estrutura.
[...] eu estou começando a trabalhar [...] a estudar aqui e, aí, a gente se deparou com: o que a gente vai fazer? Porque lá é consulta agendada, e vinha demanda do pessoal lá querendo ser atendido por uma causa aguda e a gente pouco podia fazer e, aí, a gente se deparou com o caderno de atenção básica, com a demanda espontânea [...] e essa, a gente começou a implantar lá [...] porque a gente conseguiu manter o atendimento agendado e separou um tempo também para a demanda espontânea [...]

A questão da discussão dos saberes de núcleos profissionais em interação uns com os outros no campo da APS também foi apontada pelos participantes, o que demonstrou um pensamento coerente com o princípio da integralidade do trabalho em saúde. Nesse processo, os atos de cuidar e pensar o trabalho em saúde ultrapassam a soma de olhares dos vários núcleos profissionais para alcançar a visão do cuidado em saúde como um ato relacional, que precisa estar em sintonia com o contexto e a visão global dos usuários e das comunidades ${ }^{15}$. Esse debate entre núcleo e campo e de como executar a integração e ampliar esses conhecimentos é bastante atual e um grande obstáculo a ser superado nas formações. Esses dois conceitos, campo e núcleo, precisam estar em sintonia tanto nos processos de formação, como na dinâmica vivenciada no cotidiano de trabalho ${ }^{16}$.

Em relação às modalidades, percebeu-se a relevância da presença física do professor e a sua responsabilidade ao nortear os conteúdos e conduzir a aprendizagem, além da interação presencial com os colegas, proporcionando o conhecimento de diferentes realidades na modalidade presencial, como ilustram algumas falas de trabalhadores/alunos participantes do curso ${ }^{17}$ :

[...] é que essa interação com o professor, né, na educação à distância é aquilo assim, ele passa a informação e acabou, né [...] $\mathrm{E}$ a gente, às vezes, quer a oportunidade de trocar informações. É trocar e-mails para poder continuar e depois pedindo informações e eles mandam pra gente: "Não, vou mandar esse aqui e tal [...]”. Essas informações eles podem passar também, não só o teórico, mas outras coisas mais da própria vivência de cada um.

Percebe-se que o formato de uma metodologia mais próxima de um modelo tradicional de ensino, incluindo o professor como centro do processo de ensino-aprendizagem, vivenciado durante anos de formação anterior e talvez já "cristalizado" no imaginário de muitas pessoas, leve-as a acreditar que a responsabilidade do processo de ensino está no professor ${ }^{17}$.

Entretanto, essa concepção, percebida por alguns participantes, também se mistura com uma pedagogia relacional ${ }^{18}$, a qual adota metodologias ativas e compreende que o conhecimento não é uma transmissão de conhecimento do professor ao aluno. A interação pode ocorrer tanto no ensino presencial, quanto na educação à distância, embora não tenha sido essa a percepção dos participantes, como visto na seguinte fala: 
Eu já tinha feito uma pós-graduação e eu achei superpobre, comparada a essa aqui. Adorei a pós, que nem a colega falou, eu não me adaptaria em fazer um curso desses como educação à distância, até pela questão de horários, tu sentar, tu lendo várias. Ah, né? [...] Sem ter a interação com o professor, com colegas, sem a gente poder discutir, sem ter outros horizontes, né [...] Porque o rico, eu acho, do presencial é essa troca de informações, essa troca de experiências [...] eu achei maravilhoso!

Já, em relação à modalidade à distância, na percepção dos participantes, a ampliação das ofertas de aperfeiçoamentos e qualificação profissional dessa proposta foi ressaltada. Essa proporciona um maior acesso aos trabalhadores que não atuam nos grandes centros, nos quais se concentra a maioria das formações em saúde, assim como ilustrado nas seguintes falas:

[...] como eu não tinha nenhuma pós-graduação ainda, nada, eu [...] achei interessante, principalmente em função de (ser) à distância [...]. Então, isso me motivou bastante, assim, de não ter que tá vindo a cada quinze [dias], né, que pra mim ia ser complicado [...]. Eu não teria como fazer esse curso presencial, Candelária fica distante, depende de tempo, de locomoção, enfim [...] então, por isso as oportunidades [...].

Um estudo sobre a opinião de tutores a respeito de cursos on-line para qualificação profissional na saúde aponta que a educação à distância proporciona uma ampliação do acesso a um maior número de alunos e institui outra dinâmica de conhecimento, partindo da prática à teoria, que se apoia na interação via ferramentas de comunicação ${ }^{19}$.

\section{Relação do curso de especialização com a prática de trabalho}

Nesse panorama, foram destacadas as percepções dos trabalhadores/ alunos a respeito da influência do processo do curso de especialização nas suas práticas de trabalho em APS. Essa categoria foi analisada conforme as possibilidades apontadas pelos participantes de estabelecer a relação do curso com a prática do trabalho, deste interferir de maneira positiva nesse contexto, e das dificuldades encontradas em tal trajetória para implantar/implementar ou colocar em prática os conhecimentos e processosde formação aprendidos na realidade de trabalho.

Referente às questões apontadas pelos participantes como possibilidades da relação do curso de especialização com a prática da APS, destaca-se a integração de teoria e prática, pois os conhecimentos foram utilizados também como ferramentas para conhecer e reconhecer a realidade local e do processo de trabalho da equipe, como mencionado na seguinte fala:

[...] eu acabo vendo bastante o trabalho da USF e o curso tem me ajudado muito a ver [...] Eu levo para minha unidade: eu fechei um dia da semana e faço reunião de equipe onde todos participam, dentistas, auxiliar de odontologia, todos os médicos, clínicos, pediatras, todos os profissionais [...]. A gente está conseguindo fechar duas horas, e a gente faz a reunião da equipe e [...] está sendo muito bom, a gente já está colhendo os frutos, na UBS, sabe [...].

$\mathrm{O}$ entendimento do ato de formar se aproxima de um processo de transformação, em que se estabelece uma relação indissociável entre o cuidado em saúde e os processos de gestão. O trabalhador de saúde é visualizado como protagonista do seu processo de trabalho, como um ator que planeja e executa as ações ${ }^{20}$.

Nesta mesma perspectiva, em ambas as turmas, essas ações foram apontadas como uma das principais contribuições para a prática de implantação e implementação de atividades educativas e coletivas em saúde. Ações estas que se diferem da lógica individualista proposta na maioria dos cursos de formação na área de saúde, as quais são ilustradas pela seguinte fala:

[...] Eu consegui implantar muitas coisas que eu aprendi [...] durante a parte de grupo que ninguém acreditava [...] até por uma questão cultural, que não era muito, não conseguia realizar na cidade, a gente conseguiu implementar, foi bem legal. A gente fez um grupo de gestantes pré-natal odontológico que nunca tinha existido nem realizado lá.

Essa iniciativa está relacionada aos resultados encontrados no questionário on-line, aplicado no início do curso, no qual 94,9\% dos trabalhadores/alunos manifestaram a expectativa de que o curso de especialização pudesse provocar mudanças na prática. O produto da aprendizagem não se refere a uma repetição mecânica, mas a uma atividade criadora, de modo que a solução não se finaliza na problematização, nem na experimentação ${ }^{21}$.

Outro aspecto relevante notado pelos trabalhadores/alunos foi o entendimento do curso como uma possibilidade de EPS, objetivando a reflexão, problematização e qualificação do processo de trabalho tanto da equipe como dos próprios profissionais. O desafio que a EPS enfrenta e pretende enfrentar é pensar o cotidiano como um lugar vivo, em que nos relacionamos e nos tornamos agentes ativos no processo; no qual o fazer no mundo do trabalho, em sua micropolítica, possa tornar essas intenções e implicações dos agentes em componentes explícitos para a constituição de uma produção de redes de discussões coletivas entre os trabalhadores e as equipes de saúde e, então, explorar essa produção como atos pedagógicos ${ }^{21}$. Tais percepções são relatadas por um dos participantes dos grupos focais:

[...] quem não faz educação permanente não consegue estudar muito fora de seus problemas. [...] $\mathrm{O}$ ano passado a gente não tinha capacitação permanente, esse ano começou, todo mês a gente tem uma palestra sobre um assunto da nossa realidade e às vezes assuntos relacionados, e, o curso, ele traz muita essa atualização para nós. Eu me formei já faz mais de 10 anos, 15 anos, então, isso aí é para mim relembrar, aprender coisas novas [...] saber que eu nunca mais vou conseguir, que ninguém nunca mais vai conseguir parar de aprender, né [...]. 
Em um dos estudos realizados sobre as contribuições de um curso no processo de trabalho dos participantes, na percepção dos profissionais, o processo de EPS desenvolvido proporcionou espaços mais democráticos de discussão, permitindo um aprendizado mais coletivo e de discussões dos conceitos relevantes para direcionar o cuidado 5 . Além disso, possibilitou disparar processos de transformação tanto na gestão como no cuidado, como apontado na seguinte fala:

[...] O pessoal está gostando, propondo, o pessoal sempre fazia as mesmas coisas, e quando se falava em algo diferente ninguém queria saber de nada [...]. Eu estou levando coisas também que eu aprendo no curso para capacitação. O nosso grupo de gestantes estava fraco e eu utilizei a ideia da colega, aquela de fazer o artesanato, eu levei e a equipe topou, porque eu não quero levar uma ideia minha e eu vou fazer sozinha, eu quero que a equipe abrace a ideia.

Quanto à contribuição do curso na prática de trabalho, também foram apontadas algumas dificuldades em desenvolver a ar ticulação da formação no cotidiano, de maneira que pudesse produzir mudanças no cenário em que estão inseridos. O vínculo de trabalho e as constantes mudanças dos profissionais das equipes foram pontos percebidos pelos trabalhadores/alunos como não facilitadores da construção de mudanças da prática, pois frequentemente novas equipes são recompostas, como se percebe nas seguintes falas:

[...] Na estratégia que eu trabalhava, não existe nenhum profissional do ano passado [...] trocou todo mundo [...] todas mudaram [...] ninguém [...] está todo mundo perdido [...] total [...] Está um horror!

O grande problema, eu acho, pelo menos na minha [...] é o vínculo empregatício. A gente está vivendo agora um dilema, um crescimento [...] Está ampliando a base, ótimo, mas [...] e o vínculo de trabalho do profissional, isso está faltando. Para mim, isso que a gente tem que buscar, é contrato da minha gestão, sem CLT, sem estatutário, nada, então, assim, a partir do momento que o gestor não quer mais trabalhar, amanhã pode ir embora, e o que eu recebo, só o proporcional de férias, proporcional de décimo terceiro, e proporcional do salário quando eu for mandado embora.

De acordo com as respostas do questionário on-line dos participantes, $42,4 \%$ possuíam vínculo de concursado/estatutário e 9,1\% de funcionário público, segundo a Consolidação das Leis do Trabalho (CLT). Os outros 45,5\% tinham um vínculo sem estabilidade, distribuídos entre: cooperativado (6,1\%), temporário (15,2\%), contratado pelo terceiro setor $(9,1 \%)$ e contratado com recibo de prestação de autônomo - RPA (3,0\%). Em um estudo com o objetivo de analisar o perfil dos profissionais que frequentavam os cursos de especialização e residência multiprofissional na ESF, foram encontrados dados semelhantes em relação ao vínculo empregatício ${ }^{13}$. Neste estudo, $47,0 \%$ dos alunos tinham contratos temporários por prestação de serviços e cargos comissionados, em contraposição aos 48\% que estavam no regime estatutário da CLT e, portanto, com direitos e estabilidade no emprego assegurados. Esse fato, muitas vezes, justifica as constantes trocas de profissionais nas equipes e, consequentemente, o comprometimento de todo o trabalho da ESF, impossibilitando a formação de vínculos e as construções de novas práticas profissionais que contribuam para a mudança do atual modelo de atenção à saúde ${ }^{13}$.

O tema EPS foi percebido pelos trabalhadores/alunos tanto como uma possibilidade de transformação e mudança de prática, como dificuldade por não haver garantia e valorização desse espaço no cotidiano. Segundo as respostas do questionário, 97,3\% de tais sujeitos referiram sentir necessidade de EPS. Entretanto, apenas 30,8\% responderam existir uma carga horária semanal ou mensal para capacitações e processos de EPS contemplados em seu cotidiano de trabalho. As falas abaixo constituem exemplos dessa situação:

[...] fazendo um curso de especialização, a gente teria direito a tanto tempo para fazer esse curso, a gente teria tipo uma dispensa de tantas horas de trabalho, né [...] e a gente não tem, nem dispensa de horário, nem diminuição da carga horária, nem abono, nem estímulo, nem ninguém sabe que tu estás fazendo um curso e o que poderia ser aproveitado pelo município.

E os gestores não querem saber de liberar meio dia [...] não [...] só que eles podiam, né [...] a gente tem que tirar férias para fazer o portfólio, porque, senão [...].

Portanto, alguns apontamentos demonstram que a percepção dos alunos é a de que muitos gestores não possuem o entendimento da EPS como um processo de produção de trabalho e que esta pode interferir nas transformações das situações do dia a dia. Ainda vivemos em uma sociedade que determina que alguns podem ter o direito de refletir, pensar e atuar, enquanto outros são pressionados a viver uma realidade alienada de cumprir tarefas e atividades, quantificando-as como produtividade e dissociadas do processo de gestão e criação ${ }^{21}$.

Ao encontro deste debate, os trabalhadores/alunos mencionaram a interferência da política e desqualificação dos gestores municipais como dificultadores do processo da implantação de diretrizes e práticas de saúde coerentes com as políticas públicas vigentes. Os principais pontos discutidos são a falta de corresponsabilização das três esferas de governo, a interferência da política local em detrimento da política de saúde, a falta de qualificação dos técnicos administrativos que estão na gestão e dos trabalhadores de saúde e a dificuldade na democratização dos espaços de gestão e controle social $^{22,23}$. As falas a seguir ilustram essas argumentações:

[...] Estava tendo um entrosamento melhor e estava sendo possível ver uma ESF engatinhar ali, no posto. Aí, logo vieram aseleições, aquela influência política na saúde [...] porque eram aqueles vereadores ou candidatos, a reeleição...ou novos, todos querendo se beneficiar de receita, encaminhamento, pedido de exame, e foi ficando insuportável o serviço [...]. 
Esse Conselho de vocês [...] é um Conselho real e estruturado, o nosso Conselho lá é tudo carta marcada [...].

O desenvolvimento do curso de especialização em Saúde da Família provocou uma série de reflexões e alterações no cotidiano de prática dos trabalhadores/alunos, tais como a reorganização do processo de trabalho da equipe (reunião de equipe e organização de agendas), a implementação de atividades coletivas, a implementação de acolhimento à demanda espontânea e uma maior compreensão do processo de trabalho de uma equipe de ESF.

Outro aspecto que também merece destaque é a percepção dos trabalhadores/alunos em relação à potência de mudança da prática no processo de formação e EPS. Contudo, apesar de a EPS ser apontada como um dispositivo interessante para reflexão e problematização, ainda existe pouca valorização e espaços garantidos.

Como limitações do estudo, destaca-se a desistência de alguns alunos durante o percurso da pesquisa, o não preenchimento do questionário on-line por todos os alunos e a diminuição de participantes no segundo grupo focal, para ambas as turmas.

\section{AGRADECIMENTOS}

À Universidade Aberta do Sistema Único de Saúde (UNA/SUS), à Universidade Federal de Ciências da Saúde de Porto Alegre (UFCSPA) e à Associação Hospitalar Moinhos de Vento, pelo apoio, pela oportunidade de estudo e pelo empenho ao desenvolvimento do curso de especialização em Saúde da Família.

\section{REFERÊNCIAS}

1. Connil EM. Ensaio histórico-conceitual sobre a Atenção Primária à Saúde: desafios para a organização de serviços básicos e da Estratégia Saúde da Família em centros urbanos no Brasil. Cad Saúde Pública. 2008;24(suppl 1):S7-S27. http://dx.doi.org/10.1590/S0102-311X2008001300002

2. Brasil. Lei n. 8.080, de 19 de setembro de 1990. Brasília: Presidência da República; 1990.

3. Brasil. Ministério da Saúde. Política Nacional da Atenção Básica. Brasília: Ministério da Saúde; 2012.

4. Motta JIJ. Educação permanente em saúde: da política do consenso à construção do dissenso [tese]. Rio de Janeiro: Universidade Federal do Rio de Janeiro; 1998

5. Lima JV, Turini B, Carvalho BG, Nunes EF, Lepre RL, Mainardes $P$, et al. A educação permanente em saúde como estratégia pedagógica de transformação das práticas: possibilidades e limites. Trab Educ Saúde. 2010;8(2):207-27.

6. Lopes SR, Piovesan ET, Melo LO, Pereira MF. Potencialidades da educação permanente para a transformação das práticas de saúde. Com Ciências Saúde. 2007;18(2):147-55.

7. Brasil. Portaria GM/MS n. 198, de 13 de fevereiro de 2004. Brasília: Ministério da Saúde; 2004.

8. Brasil. Ministério da Saúde. Política Nacional de Educação Permanente em Saúde. In: Davini MC. Enfoques, problemas e perspectivas na educação permanente dos recursos humanos de saúde. Brasília: Ministério da Saúde; 2009; p.39-59.

9. Universidade Federal de Ciências da Saúde de Porto Alegre. Projeto Pedagógico do curso de especialização em Saúde da Família. Porto Alegre: UFCPA; 2013.

10. Associação Hospitalar Moinhos de Vento. Projeto pedagógico: especialização em Saúde da Família. Porto Alegre: Instituto de Ensino e Pesquisa; 2011.

11. De Antoni C, Martins CM, Feranato ME, Simões A, Maurente VS, Costa FR, et al. Grupo focal: método qualitativo de pesquisa com adolescentes em situação de risco. Arq Bras Psicol. 2001; 53(2):38-53.

12. Bardin L. Análise de conteúdo. São Paulo: Edições 70; 2011.
13. Gil CR. Formação de recursos humanos em saúde da família: paradoxos e perspectivas. Cad Saúde Pública. 2005;21(2):490-8. http://dx.doi.org/10.1590/S0102-311X2005000200015

14. Heinzelman RS. Avaliação da efetividade de um curso de especialização em Saúde da Família para qualificação da atenção primária à saúde no Estado da Bahia. Tese (Doutorado) - Universidade Federal do Rio Grande do Sul. Porto Alegre: 2012.

15. Bonfada D, Cavalcante JR, Araújo DP, Guimarães J. A integralidade da atenção à saúde como eixo da organização tecnológica nos serviços. Cienc Saúde Coletiva. 2012;17(2):555-60. http://dx.doi.org/10.1590/S1413-81232012000200028

16. Feuerwerker LC, Sena RR. Interdisciplinaridade, trabalho multiprofissional e em equipe: sinônimos? Como se relacionam e o que têm a ver com a nossa vida? Olho Mágico. 1998;5(18):5-6.

17. Pereira AL. As tendências pedagógicas e a prática educativa nas ciências da saúde. Cad Saúde Pública. 2003;19(5):1527-34. http://dx.doi.org/10.1590/S0102-311X2003000500031

18. Becker F. Educação e construção do conhecimento. Porto Alegre: Artmed; 2001.

19. Laguardia J, Casanova A, Machado R. A Experiência de aprendizagem on-line em um curso de qualificação profissional em saúde. Trab Educ Saúde. 2010;8(1):97-122. http://dx.doi.org/10.1590/S1981-77462010000100006

20. GuedesCR,PitomboLB,BarrosME. Osprocessos deformaçãonaPolítica Nacional de Humanização: a experiência de um curso para gestores e trabalhadores daatençãobásicaemsaúde. Physis. 2009;19(4):1087-109. http://dx.doi.org/10.1590/S0103-73312009000400010

21. Bagnato $\mathrm{MH}$, Monteiro Ml. Perspectivas interdisciplinar e rizomática na formação dos profissionais da saúde. Trab Educ Saúde. 2006;4(2):247-58.

22. Merhy EE, Feuerwerker LC, Ceccim RB. Educación permanente en salud: una estrategia para intervenir en la micropolíica del trabajo en salud. Salud Col. 2006;2(2):147-60.

23. Silveira DS, Facchini LA, Siqueira FV, Piccini RX, Tomasi E, Thumé E, et al. Gestão do trabalho, da educação, da informação e comunicação na atenção básica à saúde de municípios das regiões Sul e Nordeste do Brasil. Cad Saúde Pública. 2010;26(9):1714-26. http://dx.doi.org/10.1590/0102-31X2010000900005 